\title{
Genetic Variations in the Bovine Fatty Acid Desaturase 6 (FADS6) Are Associated with Fatty Acid Composition in Hanwoo Cattle
}

\author{
Krishnamoorthy Srikanth ${ }^{1}$, Eunjin Lee ${ }^{1}$, Anam Kwan ${ }^{1}$, Youngjo Lim ${ }^{1} \&$ Hoyoung Chung ${ }^{1}$ \\ ${ }^{1}$ Animal Genomics and Bioinformatics Division, National Institute of Animal Science, Wanju, Korea \\ Correspondence: Hoyoung Chung, Animal Genomics and Bioinformatics Division, National Insitute of Animal \\ Science, 1500 K\&P road, Iseo, Wanju, Korea. Tel: 82-63-238-7303. E-mail: chung133@korea.kr
}

Received: September 8, 2016

Accepted: October 25, $2016 \quad$ Online Published: November 15, 2016

doi:10.5539/jas.v8n12p41

URL: http://dx.doi.org/10.5539/jas.v8n12p41

This work contributes to the internal project "Cooperative Research Program for Agriculture Science \& Technology Development (Number PJ01022002016)" and was supported by the National Institute of Animal Science in Rural Development Administration of Korea. K. Srikanth was supported by 2016 Postdoctoral Fellowship Program of National Institute of Animal Science, Rural Development Administration, Republic of Korea.

\begin{abstract}
The purpose of this study was to discover genetic variants in the bovine fatty acid desaturase domain family member 6 (FADS6) gene and to test for associations with fatty acid composition (FAC) as well as carcass traits such as backfat thickness (BFT) and marbling scores (MAR). 90 Hanwoo steers were used in the study, and sequence analyses detected 4 genetic variants in intron 2 (approximately 10,890 bp) of FADS6. The FADS6 SNPs showed no significant departures from HWE (Hardy-Weinberg Equilibrium) except g.57772511C $>$ T that did not have heterozygous genotypes. Genotypes of g.57770744A $>$ G and g.57772511C $>$ T were significantly associated with Vaccenic (C18:In7), Palmitoleic (C16:ln7), and Stearic (C18:0) acids. The analysis confirmed dominance and additive effects for the g.57770744A $>\mathrm{G}$ and g.57772511C $>$ T segments, respectively. A positive correlation $(31.1 \%, \mathrm{P}=0.003)$ between $\mathrm{BFT}$ and Linolenic acid $(\mathrm{C} 18: 3 \mathrm{n} 3)$ and a negative $(-36.5 \%, \mathrm{P}<$ $0.001)$ correlation between MAR and Eicosenoic acids (C20:1n9) were observed.
\end{abstract}

Keywords: single nucleotide polymorphism, FADS6, cattle, fatty acid composition

\section{Introduction}

It is an important fact that identification of genetic mutations associated with quantitative traits in domestic animal populations has been an area of keen interest due to their high correlation with production rates. Genetic variants leading to structural changes in genomic regions, may explain variations of quantitative traits loci (QTL) that are heavily subjected into the cattle breeding to maximize improvement in production rates. There is an increased interest to understand the mechanism of fat accumulation in meat as it is a major issue for the commercial meat industry due to their effect on meat quality traits such as backfat thickness (BFT) and marbling scores (MAR) even though physiological features of fat related traits are still unclear (Bartoň et al., 2010; Gerbens et al., 2001). Furthermore, BFT and MAR influences consumer preferences due to significant relationships between fat deposition and meat quality and also their effect on consumer health. Fatty acid composition (FAC), specifically the composition of monounsaturated fatty acids (MUFA), influences flavor of meat products (Laborde et al., 2001). The highest proportion of Oleic acid (C18:1), which is believed to be a critical factor for meat quality, has been reported in cattle (Westerling \& Hedrick 1979; Melton et al., 1982). In addition, several studies reported that saturated fatty acids (SFA) such as Mirystic (C14:0), Palmitic (C16:0), and Stearic acids (C18:0) influenced concentrations of lipoprotein cholesterol (Temme et al., 1997) and fat hardness points (Smith et al., 1998; Wood et al., 2004). Studies also suggested that concentrations of Oleic acid (C18:1) in beef are positively correlated with palatability (Westerling \& Hedrick, 1979) and fat softness. In addition, marbling and fat softness are major components that determine the quality grades of meat products in Hanwoo and also contribute positively to beef flavoring (Melton et al., 1982). 
PPAR- $\alpha$ pathway is a major pathway in fat metabolism, including lipogenesis and contains 4 major genes; $S C D$ (stearoyl-CoA desaturase), FASN (fatty acid synthase), ME1 (malic enzyme 1), and FADS6 (fatty acid desaturase 6). Studies focused on the discovery of genetic variations for the bovine FASN (Zhang et al., 2008; Morris et al., 2007; Yeon et al., 2013; Taniguchi et al., 2004) and SCD (Taniguchi et al., 2004; Bartoň et al., 2010) but not many reports have been made for the bovine ME1 and FADS6 genes. The FADS6 ( $\Delta-6$ desaturase, $\Delta-6$ FAD) gene, which is conserved in many animal species, is located at the bovine chromosome 19 and consists of a 933 bp coding sequences with 6 exons and corresponds to the UCSC sequence from nucleotide positions 57,766,830 to 57,782,479 (Baylor Btau_4.6.1/bosTau7). The bovine FADS6 gene contains a total of 1,341 bp nucleotides, including UTRs corresponding to 342 amino acids (protein ID, ENSBTAP00000022906).

FADS6 is involved in downstream regulation of polyunsaturated fatty acid (PUFA) that is essential for the maintenance of physiological homeostasis, biosynthesis, and interaction with nuclear receptor proteins (Zheng et al., 2004). For example, FADS6 controls production of $\gamma$-Linoleic (C18:3n-6) from Linolenic (C18:2n-6), (Zheng et al., 2004; Wathes et al., 2007) and also controls downstream processing of Stearic (C18:4), Eicosapentaenoic (C20:5n3) and Docosahexaenoic (C22:6n-3) from $\alpha$-Linolenic acids (C18:3n-3). Therefore, the present study aimed to identify variants in the bovine FADS6 that can be used to test associations with FAC and carcass traits.

\section{Method}

\subsection{Animals}

The experimental procedures and animals were approved by the ethics and welfare committee of the National Institute of Animal Science (NIAS). A total of 90 Hanwoo steers, which had average weights $(167.2 \pm 13.4 \mathrm{~kg})$ and age (206 \pm 12 day), were used in the study. The animals were from the Nonghyup Hanwoo Cooperation in Korea and were registered in the national databases and were bred through a standard breeding program under the restricted guidelines provided by NIAS in Korea. The pedigree analysis ascertained no significant genetic relationships between individuals, showing less than 0.01 inbreeding coefficients. According to the nutritional requirements from NRC (NRC, 1987), animals were fed with a commercial diet (Purina) based on a standard feeding program in NIAS. The conventional feeding program was ended at 31 months, and animals were slaughtered at a packing facility in NIAS. The longissimus muscle between $12^{\text {th }}$ and $13^{\text {th }}$ ribs was removed from carcasses to measure FAC and as also used for extracting genomic DNA. Marbling and Back Fat Thickness were scored according to the guidelines of NIAS.

\subsection{Sample Preparation}

For extraction of genomic DNA approximately 12 grams of muscle tissues between 12 and $13^{\text {th }}$ ribs were collected at the slaughter house in NIAS, and tissue samples were frozen immediately in liquid nitrogen and transferred to the laboratory in NIAS. After chopping approximately $1 \mathrm{~g}$ of the muscle the samples were placed into a tube with an extraction buffer, and genomic DNA was extracted using a commercial kit (Promega, USA) following the manufacturer's guidelines. DNA quantity and purity (A260/A280 ratio) for each sample were assessed by using a NanoDrop 1000 spectrophotometer (NanoDrop Technologies, USA) and stored in a $-70^{\circ} \mathrm{C}$ deep freezer until used.

\subsection{Measurements of FAC}

The lipids were extracted and methylated using chloroform-methanol $(2: 1, \mathrm{v} / \mathrm{v})$ following the procedures of Folch et al. (1957) and Morrison and Smith (1964), respectively. A gas chromatograph (Star 3600; Varian Technologies, USA) fitted with a fused silica capillary column, omega wax $205(30 \mathrm{~m} \times 0.32 \mathrm{~mm}$ i.d., $0.25 \mathrm{um}$ film thickness) was used to analyze the fatty acid methyl esters. The injection port and detector were maintained at $250{ }^{\circ} \mathrm{C}$ and $300{ }^{\circ} \mathrm{C}$, respectively, and results were presented as percentages of FA based on the total peak area. BFT (reported in $\mathrm{cm}$ ) and MAR ( 1 to 9) were measured for the reference group between the $12^{\text {th }}$ and $13^{\text {th }}$ rib. Basic statistics for the measurements of 20 FAC are shown in Table 2. The eicosadienoic (20:2n6), eicosatrienoic (20:3n6), eicosapentaenoic (EPA, 20:5n3), docosatetraenoic (22:4n6), docosapentaenoic (22:5n3), and docosahexaenoic (DHA, 22:6n3) were not presented among the $20 \mathrm{FAC}$ due to no observation values

In order to amplify genomic fragments for the FADS6 gene, a total of 5 primer pairs were designed based on the published sequence data from UCSC (nucleotide positions 57,766,830-57,782,479, Baylor Btau_4.6.1/bosTau7) using DNAstar version 6.0 software with options for amplification lengths $(1,200 \mathrm{bp})$ and $60 \%$ of GC contents (Table 1). Two microliters of $10 \mathrm{X}$ reaction buffer ( $10 \mathrm{mM}$ Tris, $\mathrm{pH} 8.3,50 \mathrm{mM} \mathrm{KCl}, 0.1 \%$ Triton X-100, 1.5 $\mathrm{mM} \mathrm{MgCl}_{2}$ ), $2.5 \mathrm{mM}$ dNTP, 10 pmol of each primer, $50 \mathrm{ng}$ of genomic DNA, and 1 unit of Taq DNA polymerase (Gibco BRL, Grand Island, NY) in a final volume of $20 \mathrm{ul}$ were used. After an initial denaturation at $95{ }^{\circ} \mathrm{C}$ for $2 \mathrm{~min}$, a total of 35 cycles of denaturation at $94{ }^{\circ} \mathrm{C} / 1 \mathrm{~min}$, annealing at $57.2 \sim 59.2{ }^{\circ} \mathrm{C} / 1 \mathrm{~min}$, and 
polymerization at $72{ }^{\circ} \mathrm{C} / 1.5 \mathrm{~min}$ (Life Science Technologies, USA) was performed. Individual PCR products for 90 individuals (the reference group) were purified using the Nucleotrap gel purification system (Clontech, USA) to perform a direct sequencing analysis with an ABI3730 XL Genetic Analyzer (Applied Biosystems, USA) at NIAS. The sequencing analysis was duplicated for both PCR and sequencing reactions to minimize experimental errors. After verification of genomic sequences using BLAST search that confirmed segments of the bovine FADS6 gene against an accession number (NM_001081722), individual sequences were aligned with SEQMAN program in DNAstar version 6.0 to identify nucleotide variation.

\subsection{Statistical Analysis}

The FA measurements were tested for normal distributions. A total of only 10 FAs were used for the association tests due to no measurements for the remaining FAs. The analysis of variance was conducted to investigate effects of genotypes on FAC, BFT, and MAR using the Statistical Analysis System (Guide, 1990) with general linear model procedures, and least squares means were compared using the Duncan's multiple range tests. Least squares means and standard errors for each trait according to genotypes were estimated, and residual correlations between measurements were estimated. The statistical model included a fixed effect for FADS6 genotype, age of animals as a covariate with a random effect of sires was used. Genotypic frequencies, minor allele frequencies (MAF), Hardy-Weinberg equilibrium (HWE) and information contents (IC) were estimated using Arlenquin version 3.5 and BioEdit version 7.0.

\section{Results}

\subsection{Analysis of Genetic Variants}

PCR amplifications with the 5 primer pairs produced amplicons sized from 471-537 bp in intron 2 (Table 1). As shown in Figure 1, alignments generated from direct sequencing analyses revealed that 4 nucleotide substitutions were identified with 3 primer pairs (FADS6-G1, FADS6-G3, and FADS6-G4), whereas variations were not observed with other primer pairs. Sequencing analyses confirmed nucleotide substitutions at positions 57,770,676 $(\mathrm{A}>\mathrm{C}), 57,770,744(\mathrm{~A}>\mathrm{G}), 57,772,511(\mathrm{C}>\mathrm{T})$, and 57,774,739 $(\mathrm{T}>\mathrm{C})$ based on the reference sequence of the UCSC chromosome 19 (Baylor Btau-4.6.1/bosTau7). The genotyping analysis observed that all SNP presented 3 genotypes except g.57772511C $>$ T that had CC and TT homozygous genotypes only. Due to no observations of heterozygous genotypes at g.57772511C $>\mathrm{T}$, a Chi-square test revealed a significant departure from HWE whereas other SNP loci were in equilibrium (Table 3). g.57770744A $>$ G showed the highest MAF (0.477), whereas g.57772511C > T presented the lowest MAF (0.113), resulting in a low information content (0.257) compared with other SNP which ranged from 0.394 to 0.678 .

\subsection{Allele Effects and Correlations}

As shown in Table 4, genotypes of g.57770744A $>\mathrm{G}$ and g.57772511C $>$ T explained phenotypic variations of vaccenic (C18:1n7), palmitoleic (C16:1n7) and stearic acids (C18:0), showing dominance and additive effects. Multiple mean differences of FAC were tested between genotypes, and the results presented that animals with the allele A had high proportions of vaccenic acids (C18:1n7) in muscle compared with animals having the allele G of g. $57770744 \mathrm{~A}>\mathrm{G}$. At g. $57772511 \mathrm{C}>\mathrm{T}$, animals with the allele $\mathrm{C}$ presented higher proportions of palmitoleic acids $(\mathrm{C} 16: \ln 7)$ than that of the allele $\mathrm{T}$ while allele $\mathrm{T}$ showed higher proportions of stearic acids (C18:0) than that of the allele C. This study was not able to find significant associations of identified SNPs with any carcass traits.

A significant positive $(\mathrm{r}=0.311, \mathrm{P}=0.003)$ correlation between $\mathrm{BFT}$ and linolenic acid $(\mathrm{C} 18: 3 \mathrm{n} 3)$, and a negative $(r=-0.365, P<0.0001)$ correlation between MAR and eicosenoic acid $(C 20: 1 \mathrm{n} 9)$ were firstly found in cattle. Other than these FAC, significant correlations between FAs with BFT and MAR were not detected. As expected, a significant positive correlation $(r=0.921, \mathrm{P}<0.0001)$ between BFT and MAR was determined. 
Table 1. Primer sequences, PCR conditions, and size of segments of the bovine fatty acid desaturase 6 (FADS6) gene amplified

\begin{tabular}{|c|c|c|c|c|c|c|}
\hline \multirow{2}{*}{ Segment } & \multicolumn{2}{|c|}{ Primer sequence } & \multirow{2}{*}{$\begin{array}{l}\text { Fragment } \\
\text { length (bp) }\end{array}$} & \multirow{2}{*}{$\begin{array}{l}\text { Annealing } \\
\operatorname{Tm}\left({ }^{\circ} \mathrm{C}\right)\end{array}$} & \multicolumn{2}{|c|}{ Nucleotide position } \\
\hline & Forward & Reverse & & & Forward & Reverse \\
\hline FADS6-G1 & AGCATCTAAGTGTTGGTTTCTC & TGCCGTGGTGCTACTCAG & 537 & 57.0 & $57,770,317-57,770,338$ & $57,770,736-57,770,753$ \\
\hline FADS6-G2 & CCCTTGCCCACGGACTACC & TCGCAGACACAGGGAGCAGA & 516 & 59.2 & $57,771,464-57,771,482$ & $57,771,960-57,771,979$ \\
\hline FADS6-G3 & GTGTCTGTGAGTCTGTTCCTGTTT & GGCCTGTACCCTCCCACTTA & 519 & 57.0 & $57,772,236-57,772,259$ & $57,772,743-57,772,762$ \\
\hline FADS6-G4 & CATGCGTGCAAGTGTTT & TTTTTAAGTATAGGATGTGGA & 531 & 57.4 & $57,774,390-57,774,406$ & $57,774,900-57,774,920$ \\
\hline FADS6-G5 & СТTCССТAGACTCСССТСАCTGT & CGCATGCTACGTCGATTCACTGGT & 471 & 59.2 & $57,777,849-57,777,871$ & $57,778,296-57,778,319$ \\
\hline
\end{tabular}

Note. ${ }^{1}$ The primer selection was based on sequences for genomic regions from 57,766,830-57,782,479 of the UCSC chromosome 19 (Baylor Btau_4.6.1/bosTau7).

Table 2. Composition information and basic statistics of the fatty acids measured

\begin{tabular}{lllll}
\hline Fatty acids & Mean \pm SE & Max & Min & VAR \\
\hline Myristic acid (14:0) & $3.283 \pm 0.72$ & 4.382 & 1.814 & 0.528 \\
Palmitic acid (16:0) & $26.926 \pm 1.53$ & 29.273 & 24.002 & 2.568 \\
Palmitoleic acid (16:ln7) & $4.391 \pm 1.00$ & 6.114 & 2.383 & 1.063 \\
Stearic acid (18:0) & $11.993 \pm 1.34$ & 14.641 & 10.196 & 1.972 \\
Oleic acid (18:ln9) & $50.437 \pm 2.22$ & 53.694 & 46.104 & 5.268 \\
Vaccenic acid (18:ln7) & $0.091 \pm 0.02$ & 0.142 & 0.065 & 0.001 \\
Linoleic acid (18:2n6) & $2.174 \pm 0.34$ & 2.627 & 1.752 & 0.123 \\
$\gamma$-Linoleic acid (18:3n6) & $0.052 \pm 0.01$ & 0.070 & 0.033 & 0.001 \\
Linolenic acid (18:3n3) & $0.093 \pm 0.02$ & 0.141 & 0.071 & 0.001 \\
Eicosenoic acid (20:ln9) & $0.392 \pm 0.12$ & 0.643 & 0.254 & 0.015 \\
Arachidonic acid (20:4n6) & $0.194 \pm 0.10$ & 0.382 & 0.098 & 0.011 \\
UFA & $57.816 \pm 1.80$ & 60.206 & 54.044 & 3.500 \\
MUFA & $55.318 \pm 1.95$ & 58.152 & 51.252 & 4.137 \\
PUFA & $2.501 \pm 0.43$ & 3.023 & 1.950 & 0.201
\end{tabular}

Note. A total of 6 fatty acids such as eicosadienoic (20:2n6), eicosatrienoic (20:3n6), eicosapentaenoic (EPA, 20:5n3), docosatetraenoic (22:4n6), docosapentaenoic (22:5n3), and docosahexaenoic (DHA, 22:6n3) were not presented due to no observation values.

Table 3. Summary statistics sand positional information of SNPs identified in this study

\begin{tabular}{llllll}
\hline Segment & Position $^{1}$ & SNP & Minor allele frequency (MAF) & HWE & Information contents (IC) \\
\hline FADS6-1 & 57770744 & $\mathrm{~A}>\mathrm{G}$ & 0.477 & 5.874 & 0.678 \\
FADS6-3 & 57772511 & $\mathrm{C}>\mathrm{T}$ & 0.113 & 88 & 0.257 \\
FADS6-4 & 57774739 & $\mathrm{~T}>\mathrm{C}$ & 0.365 & 0.003 & 0.394 \\
\hline
\end{tabular}

Note. ${ }^{1}$ The nucleotide positions were based on sequences for genomic regions from 57,766,830-57,782,479 of the UCSC chromosome 19 (Baylor Btau_4.6.1/bosTau7). 
Table 4. Least squared means and stander errors of fatty acid composition for each genotype from 2 FADS6 segments

\begin{tabular}{|c|c|c|c|c|c|c|c|c|c|}
\hline \multirow{2}{*}{ SNP } & \multirow{2}{*}{ Genotype } & \multirow{2}{*}{$\mathrm{N}$} & \multirow{2}{*}{$\mathrm{LSM} \pm \mathrm{SE}$} & \multirow{2}{*}{ Trait } & \multirow{2}{*}{ P-value } & \multicolumn{4}{|c|}{ Effect } \\
\hline & & & & & & Additive & P-value & Dominance & P-value \\
\hline \multirow[t]{3}{*}{ g. $57770744 \mathrm{~A}>\mathrm{G}$} & AA & 29 & $0.574 \pm 0.01^{\mathrm{ab}}$ & \multirow[t]{3}{*}{ Vaccenic $(\mathrm{C} 18: \ln 7)$} & \multirow[t]{3}{*}{0.033} & \multirow[t]{3}{*}{$0.108 \pm 0.09$} & \multirow[t]{3}{*}{0.234} & \multirow[t]{7}{*}{$0.353 \pm 0.15$} & \multirow[t]{7}{*}{0.021} \\
\hline & $\mathrm{AG}$ & 31 & $0.696 \pm 0.01^{\mathrm{a}}$ & & & & & & \\
\hline & GG & 27 & $0.465 \pm 0.01^{\mathrm{b}}$ & & & & & & \\
\hline \multirow[t]{2}{*}{ g. $57772511 \mathrm{C}>\mathrm{T}$} & $\mathrm{TT}$ & 10 & $4.448 \pm 0.23^{\mathrm{a}}$ & \multirow[t]{2}{*}{ Palmitoleic $(\mathrm{C} 16: \ln 7)$} & \multirow[t]{2}{*}{0.021} & \multirow[t]{2}{*}{$0.582 \pm 0.24$} & \multirow[t]{2}{*}{0.021} & & \\
\hline & $\mathrm{CC}$ & 77 & $5.031 \pm 0.08^{b}$ & & & & & & \\
\hline \multirow[t]{2}{*}{ g. $57772511 \mathrm{C}>\mathrm{T}$} & $\mathrm{TT}$ & 10 & $11.379 \pm 0.33^{\mathrm{a}}$ & \multirow[t]{2}{*}{ Stearic $(\mathrm{C} 18: 0)$} & \multirow[t]{2}{*}{0.025} & \multirow[t]{2}{*}{$-0.816 \pm 0.35$} & \multirow[t]{2}{*}{0.025} & & \\
\hline & $\mathrm{CC}$ & 77 & $10.562 \pm 0.12^{\mathrm{b}}$ & & & & & & \\
\hline
\end{tabular}

Note. ${ }^{\mathrm{a}, \mathrm{b}}$ Different letters represented differences between mean values of genotypes.

\section{Discussion}

\subsection{Genetic Effects on FA}

In cattle breeding industry, SNPs, in particular genes and genomic regions related to physiological mechanisms should be major target for investigating associations with various quantitative traits and to provide valuable solutions that may explain significant relationships between the genetic markers and economically important meat quality traits in cattle. The fat content, which is a major factor affecting meat quality (DeVol et al., 1988), should be a critical part of studies regarding FAC that is genetically correlated with meat traits (Suzuki et al., 2005; Suzuki et al., 2006). Genetic variations in genes such as FADS6, FASN, SCD, and ME1 which are involved in PPAR- $\alpha$ pathway, may explain variation in fat accumulation in meat and fatty acid compositional differences. Studies have showed the association of polymorphism in fatty acid biosynthetic genes like SREBP01, LXR $\alpha$, FADS1, FADS2, FADS4, and FASN with FAC and beef quality traits (Bhuiyan et al., 2009; Han et al., 2013; Matsumoto et al., 2014). FADS6 (Fatty acid desaturase 6) in the fatty acid biosynthesis pathway is a member of the fatty acid desaturase family. Previous studies, which reported genetic variants for $S C D$ (Taniguchi et al., 2004; Bartoň et al., 2010) and FASN (Zhang et al., 2008; Morris et al., 2007; Yeon et al., 2013), argued that SNP loci located within them were significantly associated with FAC. Functional study of bovine FADS6 has not been reported, but they were found to be highly similar to human FADS6. The FADS6 gene in humans is homologous to FADS2 (Stroud et al., 2009; Chen et al., 2015). FADS2 synthesizes Delta-6-desaturase (D6D) that catalyzes the first step in the synthesis of highly unsaturated fatty acid (HUFA) or LC-PUFA (Long chain-Poly unsaturated fatty acid (Stroud et al., 2009; Zheng et al., 2004). Therefore, it is necessary to investigate associations between genetic variants of FADS6 and FAC in muscle along with other genes involved in lipogenesis. Furthermore, genetic variants of FADS6 for cattle breeds as well as any other species have not been comprehensively studied. A study reported that cattle breeds may have genetically different backgrounds for C18:1 and C18:2 (Raes et al., 2001), concluding that different breeds presented different proportions of total lipid and ratios of phospholipid to total lipid. A study also reported that Holstein cattle had more docosahexaenoic acid (DHA, C22:6n3) than Aberdeen Angus (Warren et al., 2008). Consequently, cattle breeds as well as individuals may have genetic differences or differences in expression levels of the FADS6 enzyme that is responsible for conversion of FA. Therefore, without considering environmental effects, all the differences of expression levels of FADS6 may correspond to genetic variations of individuals. The present study ascertained that analyses with particular alleles of FADS6 had significantly high proportions of FA, and the results should be valuable for animal breeding areas when improvement of particular FAC in cattle populations is targeted. The present study was not able to find genetic variations in the coding regions that are responsible for changes of structural variations, but the identified 4 genetic variants at intron 2 are the first report for Hanwoo cattle.

\subsection{Correlations between FAC and Carcass Traits}

Previous demonstrations found that the proportions of oleic acid (C18:1n9), which is the predominant FA in beef, is positively correlated with meat palatability because intramuscular adipocytes are major contributors for lipid (St John et al., 1987), and the main reason may be due to lowering of melting point (Wood et al., 2008). In addition, oleic acids (C18:1n9) converted from stearic acids (C18:0) can increase fat softness because stearic acid (C18:0) is related to dictation of fat hardness (Smith et al., 1998; Wood et al., 2004). Therefore, the proportions of oleic acids (C18:1n9) in tissue are depended upon the activity of desaturase that is responsible for the conversion of SFA to MUFA. Unfortunately, a significant association was not detected between the 
identified SNPs in the FADS6 and oleic acids (C18:1n9) in this study, but the analysis confirmed that FADS6 is significantly correlated with other FAC. In fact, commercial areas that use MAR for grading of meat quality are focusing on the dietary modification to improve FAC in meat products. Therefore, it may be worthwhile to find what proportions and kinds of nutritional factors should be in diets that could stimulate enzyme activities of desaturase with the accumulation of oleic acids (C18:1n9) and intramuscular fat (IMF).

Consumers are increasingly aware, about the proportions of SFA in beef due to their negative effect on human health. Even though, conjugated linoleic acid (CLA) in beef is considered to be beneficial for human health (M. A. McGuire \& M. K. McGuire, 2000) the high concentration of SFA in beef causes negative effects on human health. Thus, manipulation of FAC in beef such as increasing the polyunsaturated fatty acid (PUFA) composition is necessary (Scollan et al., 2001; Dannenberger et al., 2005; Warren et al., 2002). In addition, a study reported that increasing the ratio of MUFA to SFA leads to increased taste. Moreover, studies found that stearic acid unlike other unsaturated fatty acid (UFA) has a neutral effect on human blood cholesterol level (Yu et al., 1995; Bonanome \& Grundy, 1988), and influences quality of meat due to a close relationship between the firmness of carcass fat and the melting point of lipids in beef (Wood et al., 2004).

Up until now, relationships between FA and BFT have not been reported for cattle breeds, but a study presented correlations between proportions of FAC (C18:1n9 and C18:2n6) and BFT in pigs (Wood et al., 1989). Their major finding was that BFT was positively correlated with oleic acid (C18:1) and negatively correlated with linoleic acids (C18:2n6). The present analysis agreed the directions of correlations for oleic acid (C18:1) and linoleic acid (C18:2n6) with BFT without significances. In addition, this analysis found a significant positive correlation $(\mathrm{r}=0.311, \mathrm{P}=0.003)$ between BFT and linolenic $(\mathrm{C} 18: 3 \mathrm{n} 3)$ acid. A positive correlation $(\mathrm{r}=0.201, \mathrm{P}$ $=0.064)$ was also observed between BFT and stearic acid (C18:0) similar to a previous study that showed that BFT showed a positive (C18:0 and $\mathrm{C} 18: 1 \mathrm{n} 9)$ and negative (C18:2n6 and $\mathrm{C} 18: 3 \mathrm{n} 3)$ correlations (Wood et al., 1989). A negative genetic correlation $(r=-0.365, P=0.0005)$ between MAR and eicosenoic acids $(20: 1 \mathrm{n} 9)$ was also identified in this study, the results, here should be a useful reference for cattle, and this is the first report about correlation between FAC and carcass traits in Hanwoo cattle. Therefore, the results of this study suggest that the identified genetic variants of FADS6 may be used as molecular markers for animal improvement.

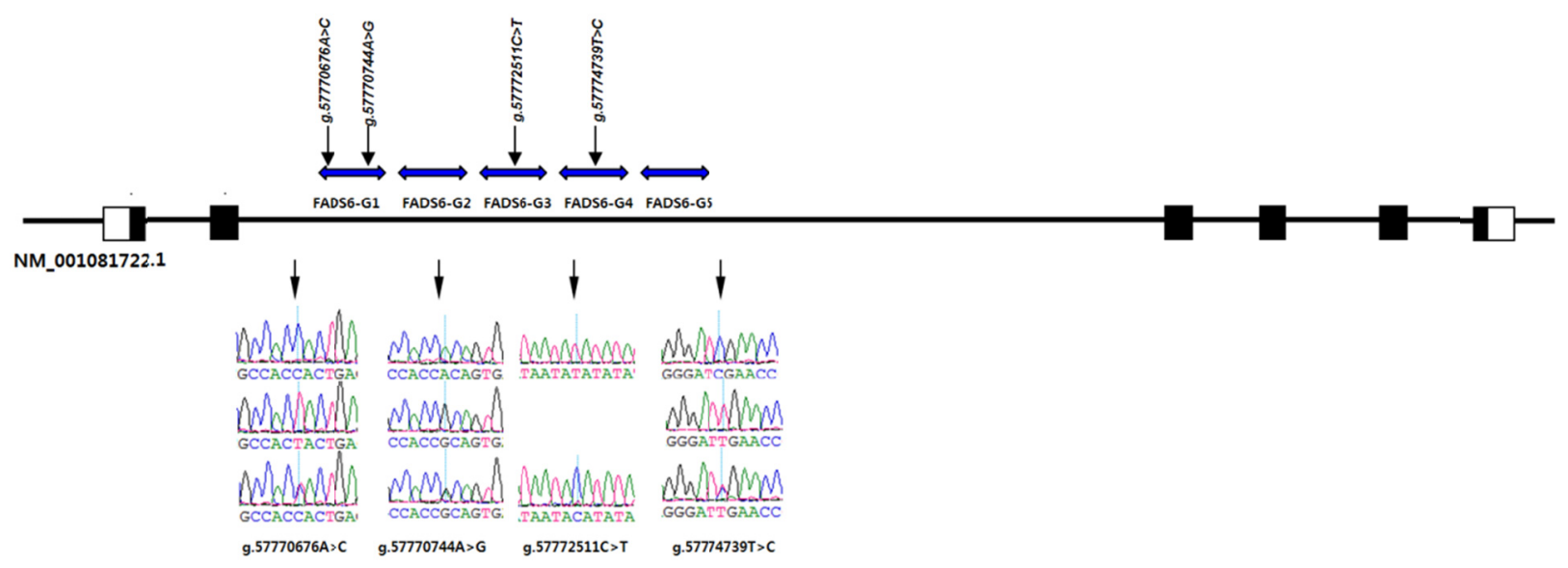

Figure 1. Map showing the identified SNP for the bovine fatty acid desaturase 6 (FADS6) gene in Hanwoo based on sequences for genomic regions from 57,766,830-57,782,479 of the UCSC chromosome 19

(Baylor Btau_4.6.1/bosTau7)

\section{References}

Bartoň, L., Kott, T., Bureš, D., Řehák, D., Zahradkova, R., \& Kottova, B. (2010). The polymorphisms of stearoyl-CoA desaturase (SCD1) and sterol regulatory element binding protein-1 (SREBP-1) genes and their association with the fatty acid profile of muscle and subcutaneous fat in Fleckvieh bulls. Meat Science, 85, 15-20. http://dx.doi.org/10.1016/j.meatsci.2009.11.016

Bhuiyan, M. S. A., Yu, S. L., Jeon, J. T., Yoon, D., Cho, Y. M., Park, E. W., ... Lee, J. H. (2009). DNA polymorphisms in SREBF1 and FASN genes affect fatty acid composition in Korean cattle (Hanwoo). Asian-Aust J Anim Sci, 22, 765-773. http://dx.doi.org/10.5713/ajas.2009.80573 
Bonanome, A., \& Grundy, S. M. (1988). Effect of dietary stearic acid on plasma cholesterol and lipoprotein levels. New England Journal of Medicine, 318, 1244-1248. http://dx.doi.org/10.1056/NEJM1988051 23181905

Chen, H., Hao, G., Wang, L., Wang, H., Gu, Z., Liu, L., ... Chen, Y. Q. (2015). Identification of a critical determinant that enables efficient fatty acid synthesis in oleaginous fungi. Scientific Reports, 5. http://dx.doi.org/10.1038/srep 11247

Dannenberger, D., Nuernberg, K., Nuernberg, G., Scollan, N., Steinhart, H., \& Ender, K. (2005). Effect of pasture vs. concentrate diet on CLA isomer distribution in different tissue lipids of beef cattle. Lipids, 40, 589-598. http://dx.doi.org/10.1007/s11745-005-1420-2

DeVol, D., McKeith, F., Bechtel, P. J., Novakofski, J., Shanks, R., \& Carr, T. (1988). Variation in composition and palatability traits and relationships between muscle characteristics and palatability in a random sample of pork carcasses. Journal of Animal Science, 66, 385-395. http://dx.doi.org/10.2527/jas1988.662385x

Folch, J., Lees, M., Sloane-Stanley, G. H., et al. (1957). A simple method for the isolation and purification of total lipids from animal tissues. J Biol Chem, 226, 497-509.

Gerbens, F., Verburg, F., Van Moerkerk, H., Engel, B., Buist, W., Veerkamp, J., \& Te Pas, M. (2001). Associations of heart and adipocyte fatty acid-binding protein gene expression with intramuscular fat content in pigs. Journal of Animal Science, 79, 347-354. http://dx.doi.org/10.2527/2001.792347x

Guide, S. P. (1990). Version 6. Cary, NC: SAS Institute.

Han, C., Vinsky, M., Aldai, N., Dugan, M. E. R., McAllister, T. A., \& Li, C. (2013). Association analyses of DNA polymorphisms in bovine SREBP-1, LXR $\alpha$, FADS1 genes with fatty acid composition in Canadian commercial crossbred beef steers. Meat Science, 93, 429-436. http://dx.doi.org/10.1016/j.meatsci.2012. 10.006

Laborde, F., Mandell, I., Tosh, J., Wilton, J., \& Buchanan-Smith, J. (2001). Breed effects on growth performance, carcass characteristics, fatty acid composition, and palatability attributes in finishing steers. Journal of Animal Science, 79, 355-365. http://dx.doi.org/10.2527/2001.792355x

Matsumoto, H., Nogi, T., Tabuchi, I., Oyama, K., Mannen, H., \& Sasazaki, S. (2014). The SNPs in the promoter regions of the bovine FADS2 and FABP4 genes are associated with beef quality traits. Livestock Science, 163, 34-40. http://dx.doi.org/10.1016/j.livsci.2014.02.016

McGuire, M. A., \& McGuire, M. K. (2000). Conjugated linoleic acid (CLA): A ruminant fatty acid with beneficial effects on human health. Journal of Animal Science, 77, 1-8. http://dx.doi.org/10.2527/jas2000. 00218812007700ES0033x

Melton, S., Black, J., Davis, G., \& Backus, W. (1982). Flavor and selected chemical components of ground beef from steers backgrounded on pasture and fed corn up to 140 days. Journal of Food Science, 47, 699-704. http://dx.doi.org/10.1111/j.1365-2621.1982.tb12694.x

Morris, C. A., Cullen, N. G., Glass, B. C., Hyndman, D. L., Manley, T. R., Hickey, S. M., ... Lee, M. A. (2007). Fatty acid synthase effects on bovine adipose fat and milk fat. Mammalian Genome, 18, 64-74. http://dx.doi.org/10.1007/s00335-006-0102-y

Morrison, W. R., \& Smith, L. M. (1964). Preparation of fatty acid methyl esters and dimethylacetals from lipids with boron fluoride-methanol. Journal of Lipid Research, 5, 600-608. http://dx.doi.org/10.1007/s00335006-0102-y

NRC. (1987). Predicting feed intake of food-producing animals. National Academies Press.

Raes, K., De Smet, S., \& Demeyer, D. (2001). Effect of double-muscling in Belgian Blue young bulls on the intramuscular fatty acid composition with emphasis on conjugated linoleic acid and polyunsaturated fatty acids. Animal Science-Glasgow, 73, 253-260. http://dx.doi.org/10.1007/s00335-006-0102-y

Scollan, N. D., Choi, N.-J., Kurt, E., Fisher, A. V., Enser, M., \& Wood, J. D. (2001). Manipulating the fatty acid composition of muscle and adipose tissue in beef cattle. British Journal of Nutrition, 85, 115-124. http://dx.doi.org/10.1079/BJN2000223

Smith, S. B., Yang, A., Larsen, T. W., \& Tume, R. K. (1998). Positional analysis of triacylglycerols from bovine adipose tissue lipids varying in degree of unsaturation. Lipids, 33, 197-207. http://dx.doi.org/10.1007/ s11745-998-0196-8 
St John, L., Young, C., Knabe, D., Thompson, L., Schelling, G., Grundy, S., \& Smith, S. (1987). Fatty acid profiles and sensory and carcass traits of tissues from steers and swine fed an elevated monounsaturated fat diet. Journal of Animal Science, 64, 1441-1447. http://dx.doi.org/10.2527/jas1987.6451441x

Stroud, C. K., Nara, T. Y., Roqueta-Rivera, M., Radlowski, E. C., Lawrence, P., Zhang, Y., ... Nakamura, M. T. (2009). Disruption of FADS2 gene in mice impairs male reproduction and causes dermal and intestinal ulceration. Journal of Lipid Research, 50, 1870-1880. http://dx.doi.org/10.1194/jlr.m900039-jlr200

Suzuki, K., Irie, M., Kadowaki, H., Shibata, T., Kumagai, M., \& Nishida, A. (2005). Genetic parameter estimates of meat quality traits in Duroc pigs selected for average daily gain, longissimus muscle area, backfat thickness, and intramuscular fat content. Journal of Animal Science, 83, 2058-2065. http://dx.doi.org/ $10.2527 / 2005.8392058 \mathrm{x}$

Suzuki, K., Ishida, M., Kadowaki, H., Shibata, T., Uchida, H., \& Nishida, A. (2006). Genetic correlations among fatty acid compositions in different sites of fat tissues, meat production, and meat quality traits in Duroc pigs. Journal of Animal Science, 84, 2026-2034. http://dx.doi.org/10.2527/2005.8392058x

Taniguchi, M., Utsugi, T., Oyama, K., Mannen, H., Kobayashi, M., Tanabe, Y., ... Tsuji, S. (2004). Genotype of stearoyl-CoA desaturase is associated with fatty acid composition in Japanese Black cattle. Mammalian Genome, 15, 142-148. http://dx.doi.org/10.1007/s00335-003-2286-8

Temme, E., Mensink, R. P., \& Hornstra, G. (1997). Effects of medium chain fatty acids (MCFA), myristic acid, and oleic acid on serum lipoproteins in healthy subjects. Journal of Lipid Research, 38, 1746-1754.

Warren, H. E., Scollan, N. D., Hallett, K. G., Enser, M., Richardson, R. I., Nute, G. R., \& Wood, J. D. (2002). The effects of breed and diet on the lipid composition and quality of bovine muscle. Proceedings of the $48^{\text {th }}$ congress of Meat Science and Technology, 1, 370-371.

Warren, H., Scollan, N., Enser, M., Hughes, S., Richardson, R., \& Wood, J. (2008). Effects of breed and a concentrate or grass silage diet on beef quality in cattle of 3 ages. I: Animal performance, carcass quality and muscle fatty acid composition. Meat Science, 78, 256-269. http://dx.doi.org/10.1016/j.meatsci. 2007.06.008

Wathes, D. C., Abayasekara, D. R. E., \& Aitken, R. J. (2007). Polyunsaturated fatty acids in male and female reproduction. Biology of Reproduction, 77, 190-201. http://dx.doi.org/10.1095/biolreprod.107.060558

Westerling, D. B., \& Hedrick, H. (1979). Fatty acid composition of bovine lipids as influenced by diet, sex and anatomical location and relationship to sensory characteristics. Journal of Animal Science, 48, 1343-1348. http://dx.doi.org/10.2527/jas1979.4861343x

Wood, J., Enser, M., Fisher, A., Nute, G., Sheard, P., Richardson, R., ... Whittington, F. (2008). Fat deposition, fatty acid composition and meat quality: A review. Meat science, 78, 343-358. http://dx.doi.org/10.1016/ j.meatsci.2007.07.019

Wood, J., Enser, M., Whittington, F., Moncrieff, C., \& Kempster, A. (1989). Backfat composition in pigs: Differences between fat thickness groups and sexes. Livestock Production Science, 22, 351-362. http://dx.doi.org/10.1016/0301-6226(89)90066-3

Wood, J., Richardson, R., Nute, G., Fisher, A., Campo, M., Kasapidou, E., ... Enser, M. (2004). Effects of fatty acids on meat quality: a review. Meat Science, 66, 21-32. http://dx.doi.org/10.1016/S0309-1740(03)00022-6

Yeon, S., Lee, S., Choi, B., Lee, H., Jang, G., Lee, K., ... Chung, H. (2013). Genetic variation of FASN is associated with fatty acid composition of Hanwoo. Meat Science, 94, 133-138. http://dx.doi.org/10.1016/j.meatsci.2013.01.002

Yu, S., Derr, J., Etherton, T. D., \& Kris-Etherton, P. M. (1995). Plasma cholesterol-predictive equations demonstrate that stearic acid is neutral and monounsaturated fatty acids are hypocholesterolemic. The American Journal of Clinical Nutrition, 61, 1129-1139.

Zhang, S., Knight, T. J., Reecy, J. M., \& Beitz, D. C. (2008). DNA polymorphisms in bovine fatty acid synthase are associated with beef fatty acid composition1. Anim Genet, 39, 62-70. http://dx.doi.org/10.1111/j.13652052.2007.01681.x

Zheng, X., Seiliez, I., Hastings, N., Tocher, D. R., Panserat, S., Dickson, C., ... Teale, A. (2004). Characterization and comparison of fatty acyl $\Delta 6$ desaturase cDNAs from freshwater and marine teleost fish species. Comparative Biochemistry and Physiology Part B: Biochemistry and Molecular Biology, 139, 269-279. http://dx.doi.org/10.1016/j.cbpc.2004.08.003 


\section{Copyrights}

Copyright for this article is retained by the author(s), with first publication rights granted to the journal.

This is an open-access article distributed under the terms and conditions of the Creative Commons Attribution license (http://creativecommons.org/licenses/by/4.0/). 